\title{
Perforin gene PRF1 c.900C> T polymorphism and HIV-1 vertical transmission
}

\author{
Luisa Zupin ${ }^{1}$ D , Vania Polesello ${ }^{2}$, Anselmo Jiro Kamada ${ }^{3}$, Rossella Gratton ${ }^{2}$, Ludovica Segat ${ }^{2}$, Louise \\ $\mathrm{Kuhn}^{4}$ and Sergio Crovella ${ }^{1,2}$ \\ ${ }^{I}$ Department of Medicine, Surgery and Health Sciences, University of Trieste, Trieste, Italy. \\ ${ }^{2}$ Institute for Maternal and Child Health IRCCS "Burlo Garofolo", Trieste, Italy. \\ ${ }^{3}$ Departmento de Genética, Universide Federal de Pernambuco, Recife, PE, Brazil. \\ ${ }^{4}$ Gertrude H. Sergievsky Center and Department of Epidemiology, Mailman School of Public Health, \\ Columbia University, New York, NY, USA.
}

\begin{abstract}
Perforin-1, a component of the immune system, is able to control Human Immunodeficiency Virus-1 (HIV-1) replication and could be involved in HIV-1 mother-to-child transmission (MTCT). This study aims at evaluating the role of the c.900C > T PRF1 gene (encoding for perforin-1) polymorphism (rs885822) in HIV-1 MTCT. The PRF1 c.900C > T polymorphism was genotyped in 331 children from Zambia using a Taqman probe on a Real Time PCR platform. The PRF1 C.900C > T C/T genotype was more frequent among HIV-1 exposed but non-infected children than in HIV-1 positive cases, and the results were confirmed among children infected during breastfeeding. PRF1 c.900C $>$ T correlated with protection against HIV-1 MTCT, suggesting its role in HIV-1 vertical transmission.
\end{abstract}

Keywords: PRF1, perforin, HIV-1 susceptibility.

Received: August 22, 2018; Accepted: February 04, 2019.

Perforin-1 (pore forming protein) is a protein present in the granules of cytotoxic T lymphocytes (CTLs) and natural killer (NK) cells (Heintel et al., 2002). In the presence of calcium, Perforin-1 polymerizes and forms channels in the target cell membrane through which other components of lytic granules including granzyme A, granzyme B and granulysin may enter in the cells (Shresta et al., 1998; Stenger et al., 1999). Therefore, Perforin-1 is one of the fundamental components of the death machinery of CTLs. CTLs possess anti-viral activity and in Human Immunodeficiency Virus-1 (HIV-1) infection they could concur in the control of viremia both during the initial and the persistent phases of infection (Musey et al., 1997; Ogg et al., 1998). The fraction of perforin-expressing HIV-1 specific CD8+ T cells inversely correlates with the peripheral blood CD4+ T cell count thus being a marker for disease progression (Shresta et al., 1998).

Perforin-1 expression in ex vivo HIV-specific CD8+ $\mathrm{T}$ cells was described as higher in healthy controls compared to patients with uncontrolled viral replication, and an inverse correlation between perforin- 1 expression in HIVspecific CD8+ T cells and viral load was observed (Migueles et al., 2008; Hersperger et al., 2010). Perforin-1 is encoded by the PRF1 gene, located at 10q22, and one poly-

Send correspondence to Luisa Zupin. Department of Medicine, Surgery and Health Sciences, University of Trieste, Trieste, 34100, Italy. E-mail: luisa.zupin@ burlo.trieste.it. morphism, namely c.900C $>\mathrm{T}$ (rs885822), was previously associated with HIV-1 vertical transmission in a Brazilian population (Padovan et al., 2011). In the present study, PRF1 c.900C $>$ T was analyzed in a population of HIV-1 exposed (infected and uninfected) children from Zambia in order to replicate previous findings, contributing to disclose its possible involvement in HIV-1 mother to child transmission (MTCT).

In this study, a subset of the population enrolled in the Zambia Exclusive Breastfeeding Study (ZEBS, Lusaka Zambia ClinicalTrials.gov Identifier: NCT00310726) was recruited. Briefly, ZEBS is a randomized clinical trial implied in the investigation of the relationship between the time of breastfeeding (i.e. exclusive breastfeeding up to 4 months, or breastfeeding with a median of 16 months) and the risk of HIV-1 transmission and child mortality. Between May 2001 and September 2004, 958 HIV-1 positive women were followed during pregnancy up to the delivery and until 24 months postpartum (PP) with their infants. Newborns were tested for HIV-1. All women were counseled to breastfeed to at least 4 months, and then half of them were randomized to stop breastfeeding and the other half to continue it. Women received only a single-dose nevirapine as prophylaxis to prevent HIV-1 MTCT.

For this analysis, 331 infants were selected, 22 had intrauterine (IU) HIV-1 transmission (defined as a positive polymerase chain reaction (PCR) result within 2 days of 
birth), 25 had intrapartum (IP) HIV-1 MTCT (defined as a positive PCR result within 42 days of birth with an earlier negative result), and 38 had postnatal (breastfeeding) HIV-1 MTCT (defined as a positive PCR results older than 42 days with a negative earlier result in a breastfed child), 246 were HIV-1 exposed but uninfected children (designed as HIV-). All women provided a written informed consent allowing children to participate in the study. All the experiments and procedures have been performed in accordance with ethical standards of the 1975 Declaration of Helsinki ( $7^{\text {th }}$ revision 2013) and the Ethics Committee of IRCCS Burlo Garofolo approved the research (protocol L-1106 1 May 2010).

DNA was extracted as reported by Segat et al. (2014). The PRF1 polymorphism was detected using TaqMan SNPs genotyping $C_{\_} \quad 1799201 \_10$ assay and TaqMan ${ }^{\circledR}$ GTXpress Master Mix with the ABI7900HT Real Time PCR platform (Applied Biosystems - Life Technologies, Carlsbad, CA U.S.A.) following the manufacturer's instructions.

The PRF1 allele and genotype frequencies were calculated by direct counting. Fisher's exact test was used for pairwise comparison of allele and genotypes. Logistic regression and Wald's test were conducted to examine the association between polymorphism genotypes and the risk of
HIV-1 MTCT. The statistical tests were performed with the free software R version 3.1.3 (R Core Team, 2018). Posthoc power calculations were performed with $G^{*}$ Power software version 3.1.9.2 using post-hoc calculation employing Fisher's exact test (Faul et al., 2007).

The PRF1 c. $900 \mathrm{C}>\mathrm{T} \mathrm{C} / \mathrm{T}$ genotype was more frequent among HIV - compared to HIV+ children, and was associated with decreased risk of acquiring HIV-1 infection ( $p=0.03, \mathrm{OR}=0.47, \mathrm{CI}=0.23-0.94 ;$ power $=0.68$; Table 1 and Table S1) also after adjustment for maternal CD4 cells count and HIV-1 plasma viral load $(p=0.01, \mathrm{OR}=0.40$, $\mathrm{CI}=0.19-0.81$; data not shown). When children were subdivided according to the route of transmission, $\mathrm{C}$ allele and $\mathrm{C} / \mathrm{T}$ genotype correlated with protection towards HIV-1 MTCT in the group of PP infected children ( $\mathrm{C}$ allele: $p=0.02, \mathrm{OR}=0.35, \mathrm{CI}=0.11-0.90$; power $=0.64$; and $\mathrm{C} / \mathrm{T}$ genotype: $p=0.01, \mathrm{OR}=0.22, \mathrm{CI}=0.04-0.74$; power $=0.50$; Table 1 and Table S1) also after adjustment for maternal CD4 cells count and HIV-1 plasma viral load $(p=0.009$, $\mathrm{OR}=0.19, \mathrm{CI}=0.05-0.66$; data not shown).

Our results partially agree with those of Padovan et al. (2011). In fact, both studies observed an increased frequency of $\mathrm{c} .900 \mathrm{C}>\mathrm{T} \mathrm{T}$ allele in the HIV -1 positive children group if compared to the group of HIV-1 exposed but not infected children. Our study found the c. $900 \mathrm{C}>\mathrm{T}$ T/T geno-

Table 1 - PRF1 polymorphism allele genotype frequencies (and counts) in HIV-1 exposed but not infected children (HIV-) and HIV-1 infected children $(\mathrm{HIV}+)$ stratifying for timing of HIV-1 mother to child transmission (MTCT) in intrauterine (IU) intrapartum (IP) and postpartum (PP) groups.

\begin{tabular}{|c|c|c|c|c|c|c|c|c|c|}
\hline \multirow[t]{2}{*}{ Children } & HIV+ & IU & IP & PP & HIV- & \multirow[t]{2}{*}{$\begin{array}{l}\text { HIV+ vs. } \\
\text { HIV- }\end{array}$} & \multirow[t]{2}{*}{ IU vs. HIV- } & \multirow[t]{2}{*}{ IP vs. HIV- } & \multirow[t]{2}{*}{ PP vs. HIV- } \\
\hline & $\mathrm{n}=85$ & $\mathrm{n}=22$ & $\mathrm{n}=25$ & $\mathrm{n}=38$ & $\mathrm{n}=246$ & & & & \\
\hline \multicolumn{10}{|l|}{ PRF1 } \\
\hline \multicolumn{10}{|c|}{$\begin{array}{l}\text { c. } 900 \mathrm{C}>\mathrm{T} \\
\mathrm{rs} 885822\end{array}$} \\
\hline $\mathrm{T}$ & $0.89(151)$ & $0.82(36)$ & $0.88(44)$ & $0.93(71)$ & $0.83(410)$ & Ref. & Ref. & Ref. & Ref. \\
\hline $\mathrm{C}$ & $0.11(19)$ & $0.18(8)$ & $0.12(6)$ & $0.07(5)$ & $0.17(82)$ & $\begin{array}{c}p=0.11 \\
\mathrm{CI}=0.35-1.09 \\
\quad \mathrm{OR}=0.63\end{array}$ & $\begin{array}{c}p=0.83 \\
\mathrm{CI}=0.43-2.55 \\
\mathrm{OR}=1.11\end{array}$ & $\begin{array}{c}p=0.54 \\
\mathrm{CI}=0.23-1.68 \\
\mathrm{OR}=0.68\end{array}$ & $\begin{array}{c}p=0.02 ; \\
\mathrm{CI}=0.11-0.90 ; \\
\mathrm{OR}=0.35\end{array}$ \\
\hline $\mathrm{T} / \mathrm{T}$ & $0.81(69)$ & $0.73(16)$ & $0.76(19)$ & $0.87(34)$ & $0.70(171)$ & Ref. & Ref. & Ref. & Ref. \\
\hline $\mathrm{C} / \mathrm{T}$ & $0.15(13)$ & $0.18(4)$ & $0.24(6)$ & $0.13(3)$ & $0.28(68)$ & $\begin{array}{c}p=0.03 \\
\mathrm{CI}=0.23-0.94 \\
\quad \mathrm{OR}=0.47\end{array}$ & $\begin{array}{c}p=0.60 \\
\mathrm{CI}=0.15-2.05 \\
\mathrm{OR}=0.63\end{array}$ & $\begin{array}{c}p=0.82 ; \\
\mathrm{CI}=0.25-2.18 \\
\mathrm{OR}=0.79\end{array}$ & $\begin{array}{c}p=0.01 ; \\
\mathrm{CI}=0.04-0.74 \\
\mathrm{OR}=0.22\end{array}$ \\
\hline $\mathrm{C} / \mathrm{C}$ & $0.04(3)$ & $0.09(2)$ & $0.00(0)$ & $0.004(1)$ & $0.03(7)$ & $\begin{array}{c}p=1.00 \\
\mathrm{CI}=0.17-4.82 \\
\quad \mathrm{OR}=1.06\end{array}$ & $\begin{array}{c}p=0.19 ; \\
\mathrm{CI}=0.28-17.83 \\
; \mathrm{OR}=3.03\end{array}$ & n.c. & $\begin{array}{c}p=1.00 ; \\
\mathrm{CI}=0.01-5.90 \\
\mathrm{OR}=0.72\end{array}$ \\
\hline HWE & $\begin{array}{l}\chi^{2}=4.48 \\
\mathrm{p}=0.03\end{array}$ & $\begin{array}{l}\chi^{2}=3.33 \\
p=0.07\end{array}$ & $\begin{array}{l}\chi^{2}=0.46 \\
p=0.49\end{array}$ & $\begin{array}{l}\chi^{2}=4.86 \\
p=0.03\end{array}$ & $\begin{array}{l}\chi^{2}=0.01 \\
p=0.94\end{array}$ & & & & \\
\hline
\end{tabular}

HWE $=$ Hardy Weinberg equilibrium

HIV $-=$ HIV-1 exposed but not infected children

HIV $+=$ HIV -1 infected children

IU = intrauterine HIV-1 mother to child transmission

IP = intrapartum HIV-1 mother to child transmission

$\mathrm{PP}=$ postpartum HIV-1 mother to child transmission

$\mathrm{OR}=$ odds ratio

$\mathrm{CI}=$ confidence interval

n.c. $=$ not calculable 
type to be more frequent among $\mathrm{HIV}+$ respect to $\mathrm{T} / \mathrm{C}$ genotype, while in the study of Padovan et al. (2011) T/T was more frequent compared to $\mathrm{C} / \mathrm{C}$ homozygous genotype. The study of McIllroy et al. (2006) also analyzed this PRF1 gene polymorphism in a cohort of French HIV+ seroconverters. They observed that PRF1 c. $900 \mathrm{C}>\mathrm{T}$ polymorphism seemed not to alter the amino acidic sequence of perforin-1 protein and was not associated with HIV-1 infection or progression. The different mode of HIV-1 transmission and different ethnic genomic background could account for the divergent results.

In the current study, we observed an association of PRF1 polymorphism with the susceptibility to HIV-1 in the $\mathrm{HIV}+$ group, but intriguingly, it was confirmed only in the infants that presented PP MTCT, thus indicating a protective effect of the variants at birth and not during the pregnancy or the delivery.

The functional effect of this polymorphism on the protein and its possible influence in HIV-1 vertical transmission were not yet reported. A hypothesis suggested by Padovan et al. (2011) indicated the PRF1 c.900C $>$ T polymorphism as exerting possible effects on protein expression, which might in turn influence NK functionality. Indeed, the NK response plays a pivotal role in preventing HIV-1 vertical transmission, as a higher HIV-1 specific NK response was found in HIV-1-infected non transmitter mothers and exposed-uninfected children compared to transmitter mothers and exposed-infected children (Tiemessen et al., 2009). However, this speculation should be confirmed by functional analysis, which have not been performed in our study due to the fact that the sole biological material available were dried blood spots.

We are aware that the small sample size of our population could have influenced the statistical analysis, especially in the subgroups classified according to the route of MTCT. However, the quite high power of the statistically significant associations allows us to be confident about the statistical relevance of the results. We also decided to not perform corrections for multiple testing in order to unravel all the possible associations that could be significant, especially in an infectious disease where role of genetic polymorphisms should be small, and since after applying multiple test corrections our significance will be lost.

Another point that should be taken into account is the MTCT, as even when the viral HIV-1 RNA is undetectable, the risk MTCT still exists (see for example Reliquet et al., 2014). However, the modern test for virologic diagnosis did not reveal possible infections, so possibly creating a bias in our analysis.

Considering our findings and the comparison with the two other studies analyzing the role of $P R F 1$ variants in the context of HIV-1 infection, further association studies in populations of different ethnic backgrounds are necessary to disclose the effective role of perforin-1 in HIV-1 MTCT susceptibility.

\section{Acknowledgments}

This work has been financially supported by RC08/17 grant from IRCCS Burlo Garofolo Trieste / Ministry of Health (Italy). This study was also supported in part by grants from the Eunice Kennedy Shriver, National Institute of Child Health and Human Development (NICHD), National Institutes of Health (NIH) (HD39611, HD40777, HD57617). VP was the recipient of a fellowship from IRCCS Burlo Garofolo.

\section{Conflict of interest}

The authors declared no conflict of interest.

\section{Author contributions}

LZ conducted the experiments and wrote the manuscript; VP participated in performing the experiments; AJK conducted the statistical analyses and participated in writing the manuscript; RG participated in performing the experiments; LS critically revised the manuscript and supervised the experiments; LK was responsible of the management of the patients and collected the specimens; $\mathrm{SC}$ conceived the study and critically revised the manuscript. All authors read and approved the final version.

\section{References}

Faul F, Erdfelder E, Lang AG and Buchner A (2007) G*Power 3: A flexible statistical power analysis program for the social, behavioral, and biomedical sciences. Behav Res Methods 39:175-191.

Heintel T, Sester M, Rodríguez MMB, Krieg C, Sester U, Wagner R, Pees HW, Gärtner B, Maier R and Meyerhans A (2002) The fraction of perforin-expressing HIV-specific CD8 T cells is a marker for disease progression in HIV infection. AIDS 16:1497-1501.

Hersperger AR, Pereyra F, Nason M, Demers K, Sheth P, Shin LY, Kovacs CM, Rodriguez B, Sieg SF, Teixeira-Johnson L et al. (2010) Perforin expression directly ex vivo by HIVspecific CD8 T-cells is a correlate of HIV elite control. PLoS Pathogens 6:e1000917.

McIlroy D, Meyer L, Dudoit Y, Samri A, Delfraissy J-F, Autran B, Debré P and Theodorou I (2006) Polymorphism in the proximal promoter region of the perforin gene and its impact on the course of HIV infection. Int $\mathrm{J}$ Immunogenet 33:73-79.

Migueles SA, Osborne CM, Royce C, Compton AA, Joshi RP, Weeks KA, Rood JE, Berkley AM, Sacha JB, CoglianoShutta NA et al. (2008) Lytic granule loading of CD8+ T cells is required for HIV-infected cell elimination associated with immune control. Immunity 29:1009-1021.

Musey L, Hughes J, Schacker T, Shea T, Corey L and McElrath MJ (1997) Cytotoxic-T-cell responses, viral load, and disease progression in early human immunodeficiency virus type 1 infection. N Engl J Med 337:1267-1274.

Ogg GS, Jin X, Bonhoeffer S, Dunbar PR, Nowak MA, Monard S, Segal JP, Cao Y, Rowland-Jones SL, Cerundolo V et al. (1998) Quantitation of HIV-1-specific cytotoxic T lympho- 
cytes and plasma load of viral RNA. Science 279:2103-2106.

Padovan L, Segat L and Crovella S (2011) A polymorphism in PRF1 gene is associated with HIV-1 vertical transmission in Brazilian children. AIDS 25:535-537.

R Core Team (2018) R: A Language and Environment for Statistical Computing. R Foundation for Statistical Computing, http://www.R-project.org.

Reliquet V, Winer N, Chereau N, Launay E, Lamberet A, Andre-Garnier E, Raffi F and Brunet C (2014) The spectrum of HIV mother-to-child transmission risk. J Int AIDS Soc 17:19703.

Segat L, Zupin L, Kim H-Y, Catamo E, Thea DM, Kankasa C, Aldrovandi GM, Kuhn L and Crovella S (2014) HLA-G 14 bp deletion/insertion polymorphism and mother-to-child transmission of HIV. Tissue Antigens 83:161-167.

Shresta S, Pham CT, Thomas DA, Graubert TA and Ley TJ (1998) How do cytotoxic lymphocytes kill their targets? Curr Opin Immunol 10:581-587.
Stenger S, Rosat JP, Bloom BR, Krensky AM and Modlin RL (1999) Granulysin: A lethal weapon of cytolytic T cells. Immunol Today 20:390-394.

Tiemessen CT, Shalekoff S, Meddows-Taylor S, Schramm DB, Papathanasopoulos MA, Gray GE, Sherman GG, Coovadia AH and Kuhn L (2009) Unusual NK cell responses to HIV-1 peptides are associated with protection against maternalinfant transmission of HIV-1. J Immunol 182:5914-5918.

\section{Supplementary material}

The following online material is available for this article:

Table S1 - The results from power analysis (Fisher's exact test).

Associate Editor: Mara H. Hutz

License information: This is an open-access article distributed under the terms of the Creative Commons Attribution License (type CC-BY), which permits unrestricted use distribution and reproduction in any medium, provided the original article is properly cited. 